\title{
Review: multiple interventions modestly reduce cardiovascular risk factors in primary prevention, but effects on mortality are uncertain
}

Ebrahim S, Davey Smith G. Multiple risk factor interventions for primary prevention of coronary heart disease. Cochrane Review, latest version 24 Feb 1999. In: the Cochrane Library. Oxford: Update Software.

QUESTION: In people who show no evidence of established cardiovascular disease, how effective is counselling or educational interventions aimed at controlling risk factors in reducing all cause and coronary artery disease (CAD) mortality?

\section{Data sources}

Studies were identified by using Medline (1966 to April 1995) and bibliographies of relevant studies and by contacting experts.

\section{Study selection}

Studies were selected if they were randomised controlled trials with $\geq 6$ months of follow up of counselling or educational interventions with or without medications aimed at controlling $\geq 1$ cardiovascular risk factor (blood pressure, smoking, total blood cholesterol level, physical activity, and diet) in people $\geq 40$ years of age who show no evidence of cardiovascular disease.

Sources of funding: NHS Centre for Reviews and

Dissemination and

Health Education

Authority.

For correspondence: Professor S Ebrahim, Epidemiology of

Ageing, Social

Medicine, University of

Bristol, Canynge Hall,

Whiteladies Road,

Bristol BS8 2PR, UK

Fax +44117928

7325 .

A modified version of the abstract also appears in EvidenceBased Nursing.

\section{Data extraction}

Data were extracted independently by 2 reviewers on study design aspects, patient baseline characteristics, and follow up. Outcomes were changes in blood pressure and total blood cholesterol level, smoking, all cause mortality, and CAD mortality.

\section{Main results}

18 trials (140 245 patients) were included. Heterogeneity existed among the trials for all outcomes except CAD mortality (2 trials focused on hypertensive patients). Blood pressure, total blood cholesterol level, and smoking prevalence decreased more in patients who received risk factor modification than in patients who received no intervention or usual care (table). 10
Risk factor intervention v no intervention for coronary artery disease $(C A D)^{*}$

\begin{tabular}{|c|c|c|c|c|}
\hline \multicolumn{3}{|c|}{ Outcomes (follow up range 6 mo to 12 y) } & \multicolumn{2}{|c|}{$\begin{array}{l}\text { Weighted mean } \\
\text { decrease }(95 \% \text { CI) }\end{array}$} \\
\hline \multicolumn{3}{|l|}{ Systolic blood pressure $(\mathrm{mm} \mathrm{Hg})$} & \multicolumn{2}{|c|}{$3.3(1.9$ to 4.7$)$} \\
\hline \multicolumn{3}{|l|}{ Diastolic blood pressure $(\mathrm{mm} \mathrm{Hg})$} & \multicolumn{2}{|c|}{$2.2(1.3$ to 3.1$)$} \\
\hline \multirow[t]{3}{*}{ Total blood cholesterol level (mmol/l) } & & & \multicolumn{2}{|c|}{$0.16(0.09$ to 0.24$)$} \\
\hline & \multicolumn{2}{|c|}{ Weighted event rates } & & \\
\hline & Intervention & $\begin{array}{l}\text { No } \\
\text { intervention }\end{array}$ & RRR (CI) & NNT (CI) \\
\hline $\begin{array}{l}\text { Smoking prevalence } \\
\text { (follow up range } 1 \text { to } 12 \mathrm{y} \text { ) }\end{array}$ & $34.5 \%$ & $38 \%$ & $\begin{array}{l}10 \% \\
(2 \text { to } 17) \\
\end{array}$ & $\begin{array}{l}29 \\
(14 \text { to } 200)\end{array}$ \\
\hline All cause mortality & $7.1 \%$ & $7.2 \%$ & $\begin{array}{l}5 \% \\
(-4 \text { to } 13)\end{array}$ & $\begin{array}{l}\text { Not } \\
\text { significant }\end{array}$ \\
\hline CAD mortality & $2.5 \%$ & $2.6 \%$ & $\begin{array}{c}4 \% \\
(-4 \text { to } 11)\end{array}$ & $\begin{array}{l}\text { Not } \\
\text { significant }\end{array}$ \\
\hline
\end{tabular}

*Random effects model used for all outcomes except CAD mortality. Abbreviations defined in glossary; NNT calculated from data in article. trials included clinical outcomes. All cause and CAD mortality were not reduced by risk factor modification (table).

\section{Conclusion}

In people who show no evidence of established cardiovascular disease, multiple risk factor interventions consisting of either counselling or educational interventions modestly reduce blood pressure, total blood cholesterol level, and smoking prevalence but not all cause or coronary artery disease mortality.

\section{COMMENTARY}

Ebrahim and Davey Smith conclude that counselling or education to reduce cardiovascular risk factors fails to reduce all cause mortality or mortality from CAD. This conclusion is not surprising because patients included in these studies were from the general population and at average risk for $\mathrm{CAD}$, and the trials had a median follow up of 3 years. The benefits of risk factor reduction may develop after many years.

All risk factors are not created equal. The potential benefits of behavioural approaches to reduce tobacco use in average risk patients are greater than those of counselling to alter diet or increase exercise. The cost effectiveness of smoking cessation programs is $<\$ 1000$ per life year saved. It is also important to emphasise the potential benefit of adjunctive pharmacological therapy to counselling or education. The addition of a 9 week course of sustained release bupropion, with or without nicotine replacement therapy, to a brief physician advice and counselling program may produce 1 year abstinence rates $>30 \%{ }^{2}$

Finally, not all patients are equally motivated to change their lifestyle. Intensive lifestyle changes in motivated patients with established disease can decrease cardiac events. ${ }^{3}$ The potential effect of lifestyle modification in motivated, high risk patients may be substantial.

Robert Gluckman, MD

Providence-St Vincent Medical Center Portland, Oregon, USA

1 Curry SJ, Grothaus LC, McAfee T, et al. Use and cost effectiveness of smoking-cessation services under four insurance plans in a health maintenance organization. $N$ Engl J Med 1998;339:673-9.

2 Jorenby DE, Leischow SJ, Nides MA, et al. A controlled trial of sustained-release bupropion, a nicotine patch, or both for smoking cessation. N Engl J Med 1999;340:685-91.

3 Ornish D, Scherwitz LW, Billings JH, et al. Intensive lifestyle changes for reversal of coronary heart disease. JAMA 1998;280:2001-7. 